\begin{tabular}{|c|c|}
\hline \multirow{3}{*}{ 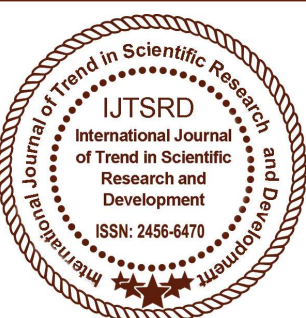 } & $\begin{array}{l}\text { International Journal of Trend in Scientific } \\
\text { Research and Development (IJTSRD) }\end{array}$ \\
\hline & International Open Access Journal \\
\hline & ISSN No: 2456 - 6470 | www.ijtsrd.com | Volume - 2 | Issue - 5 \\
\hline
\end{tabular}

\title{
Design and Development of System Integrated Test Facility for IADS
}

\author{
Asha $\mathbf{H ~ J}^{1}$, Gopalaiah ${ }^{2}$ \\ ${ }^{1}$ Student, ${ }^{2}$ Proffesor \\ Department of Instrumentation Technology, \\ Dayananda Sagar College of Engineering, Bangalore, Karnataka, India
}

\begin{abstract}
This paper proposes a design and development of system integrated test facility for Integrated Architecture Display System (IADS). The earlier system was conventional cockpit in that system had may sensor indicators for different signals it's difficult to monitoring all indicators at a time for the pilots hence the Integrated Architecture and Display System (IADS) replace the conventional cockpit on the helicopter. The proposed control scheme includes four separate control modules with DMC, MFD, DIU AND CDS, respectively. IADS is built around the digital Display and Mission Computer (DMC) and it acquires helicopter data from on-board sensors in various formats, converts them to digital format for display on the MFDs and CDUs.
\end{abstract}

Keywords: Display and Mission Computer (DMC), Control Display system (CDS), Multi-function Display (MFD), Data Interface Unit (DIU), ALH helicopter, simultaneous signals monitoring.

\section{INTRODUCTION}

The Integrated Architecture and Display System (IADS) replace the conventional Cockpit on the helicopter.

Comparison between Conventional Cockpit and Glass Cockpit (IADS)

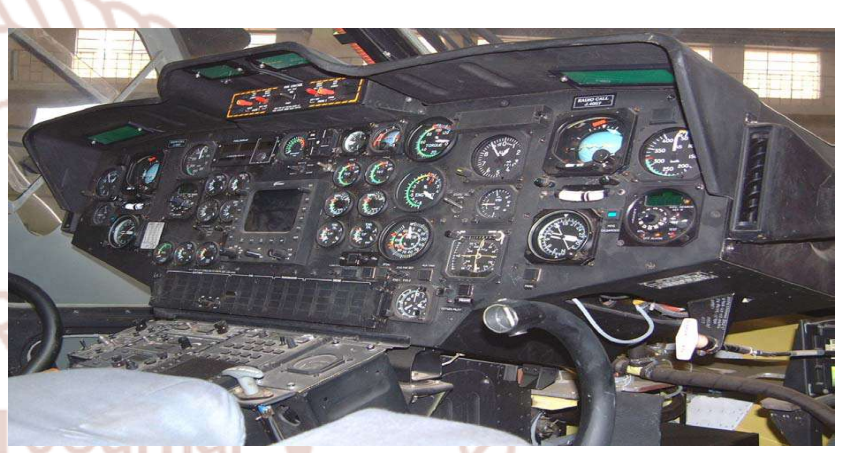

Figure 1.1: Instrument Panel with Conventional Instruments

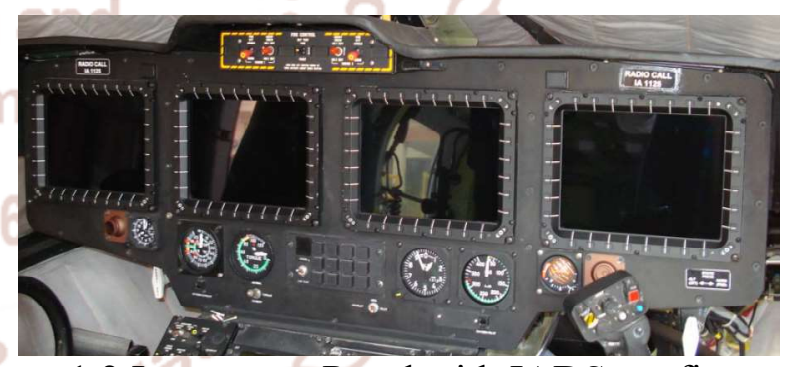

Figure 1.2 Instrument Panel with IADS configuration

IADS is built around the digital Display and Mission Computer (DMC) and it acquires helicopter data from on-board sensors in various formats, converts them to digital format for display on the MFDs and CDUs. IADS also gives outputs to various helicopter systems in the required format.

The IADS concept is to change the traditional cockpit operation with respect to the Following issues:

1. Flight instrument display.

2. Airframe and Engines systems status display.

3. Situational Awareness.

4. Weather Condition Awareness. 
5. Navigation management.

6. Communication operation.

7. Radio-navigation operation.

8. Mission systems operation.

9. Planning and Debriefing.

IADS provides following advantages:

1. Tactical Situation Awareness,

2. Reduced Crew Workload,

3. Improved Mission Effectiveness

4. Improve system safety due to extensive BIT

5. Reduced clutter in the cockpit

6. Provide flexibility for integration of new systems

The remainder of this paper is organized as follows. The modelling of the modified octorotor helicopter is described in Section II. Then, in Section III, the detailed design procedure of the proposed adaptive FTC scheme is presented. The experimental results based on the modified octorotor helicopter are followed in Section IV to demonstrate the effectiveness of the proposed control scheme. Finally, general conclusions of this paper are summarized in Section V.

\section{LITERATURE SURVEY}

The literature survey focuses on the existing methods, technologies and mechanisms implemented for IADS configuration. Initially a brief review of the literature refereed in the references is made. Subsequent sections cover the details about certain aspects in order to build the basics for understanding the work carried out in this document.

IADS configuration manual, DMC manual, CDS manual, MFD manual, DIU manual [1] most of the information I referred from these manuals are available at HAL and with this I referred some conference papers for better analysis .

Wallace, lane. "Airborne Trailblazer: two Decades with NASA Langley's 737 Flying Laboratory" NASA [2], existing method in helicopter transport operations get many problems of individual instruments. In other words, the improving numbers of cockpit elements were giving the attention for cockpit space and pilot".

Katz, peter [3] developed a helicopter design and pilot magazine-glass-cockpit layout design ideas and considered the pilot comfort between the glass cockpit how they can handle the instruments in glass cockpit.
Fred Georg [4] evaluates the merit and demerit in both glass cockpit and conventional system in both systems have some merits and demerits are discussed in this reference section.

God fey, Kara [5]" HELICOPTERS REVEALED: Pilot comes to know what REALLY goes on in a cockpit and it may give the reveals. It shows that the redundancy of the proposed system and both efficiency of the Glass cockpit".

S. A. Cavell midshipmen and quarterdeck boys in the British navy [6] to comparing the functions of others systems of glass cockpit and some systems can change the manually and some system cannot change the manually. The procedure to changing by manually in glass cockpit.

\section{IADS Architecture}

The IADS architecture is redundant and comprises the following Components:

Two Display and Mission Computers (DMC) located in the nose cone,

> Two Data Interface Units (DIU) located in cabin aft

Two Control and Display Systems (CDS) located in the center console and

Four Multi-Function Displays (MFD) located on the main instrument panel.

The IADS block diagram for army utility configuration is provided in the following figure

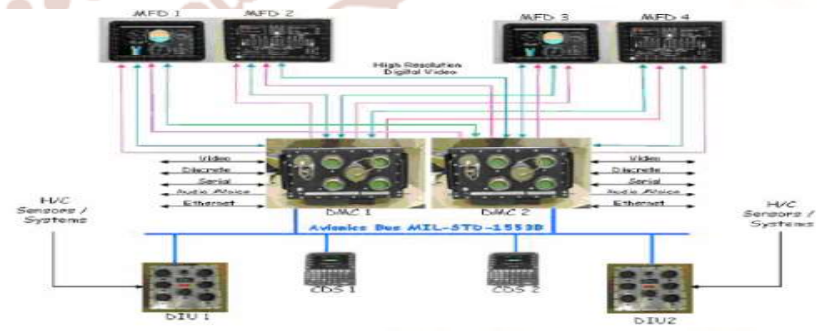

Figure 2.1: IADS block diagram

\subsection{IADS switching on procedure}

Electrical controls: The electrical control for the IADS consists of the Circuit Breakers for powering of each LRU of IADS and switches.

DMC: DMC1 is switched on when DMC1 $\mathrm{CB}$ is pushed in. DMC2 is powered on when DMC2 $\mathrm{CB}$ is pushed in. 
DIU: The DIUs are powered by DIU1 PWR, DIU1 CONT, IADS CONT CB (for DIU1) and DIU2 PWR, DIU2 CONT CB (for DIU2). However, the DIUs are switched on when the IADS1 and IADS switches are switched ON.

MFD: The MFDs are powered by MFD1, MFD2, MFD3 and MFD4 CBs respectively. However, the MFDs switch on when the IADS1 and IADS2 switches are switched ON. The MFDs also have individual ON/OFF control rocker on the right bottom row of MFD bezel for switching on and off the MFDs.

CDU: The CDUs are powered by CDS1 and CDS2 CBs. However, the CDUs switch on when the IADS1 and IADS2 switches are switched ON.

\section{A. DISPLAY AND MISSION COMPUTER (DMC)}

The DMC system is designed to be a multi-role, realtime airborne central computer suitable for avionics applications as shown in above figure 3 . Its mission is to provide the core for avionics systems designed with a centralized architectural approach, where an LRU computer may perform all avionics management, mission processing, and display functions.

The DMC/DMM is interfaced to the following avionic sub-systems:

$>$ Multi-Function Displays (MFD

$>$ Sensors

$>$ Data Transfer Device (DTD)

\section{DMC structure:-}

The 4A116-02/03 DMC is composed of four circuit card assemblies (CCA) installed in a VERSA module euro card (VME 64) bus backplane, communication between system modules is performed over the VME bus and PCI extensions allowing the various cards to access all system resources.

Slot \#1: C540 DVMM graphics and video card

Slot \#2: spare

Slot \#3: C106 SBC for Digital Moving Map in 4A116-03 configuration only.

Slot \#4: C106 SBC for Display and Mission Computer

Slot \#5: spare

Slot \#6: C437 IOM I/O card

\section{B. CONTROL DISPLAY SYSTEM (CDS)}

Control \& Display System (CDS) is a 5 inches standalone integrated display unit installed and integrated in the ALH. The CDS provides the interface for operator data entry, avionics mode selections, and system status displays. The CDS sends detected operator keyboard pushbutton inputs and commands via a redundant MIL-STD-1553B data bus.

The CDS contains the following interfaces:
A. Electrical power supply input
B. MIL-STD 1553 communication bus
C. Discrete inputs
D. USB input
E. Global Positioning System (GPS)

The unit is connected to the helicopter with one circular connector and one TNC connector.

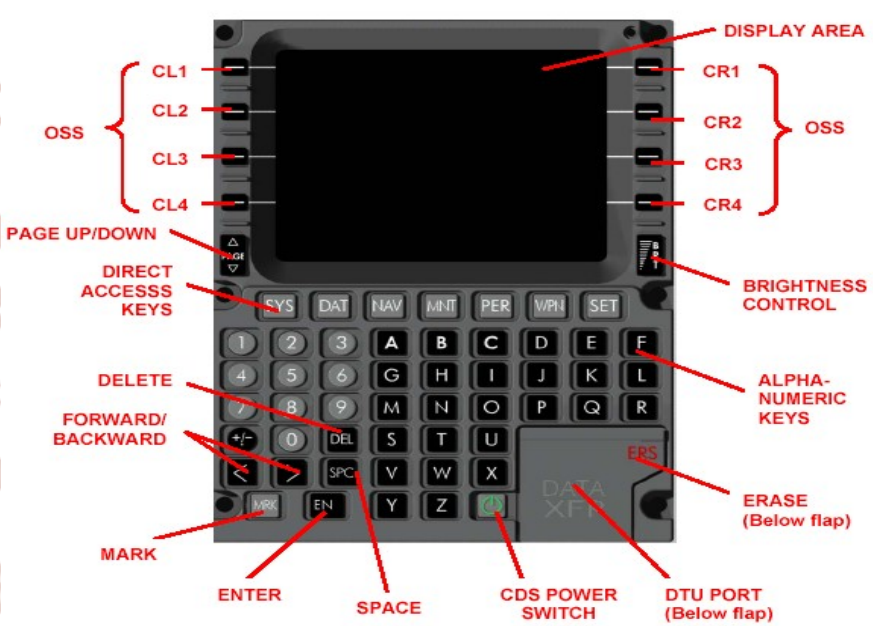

Figure2.2. cds assembly front view

\section{MULTI FUNCTIONAL DISPLAY (MFD)}

The Multi- Function Display is the main terminal display system of the helicopter's flight and navigation computer. Each helicopter includes four10.4" MFD units through which the operator can display flight data on software indicators, navigation data on digital map, real time video and any other application defined by the central computer. The MFD provides setting and update of data and interfacing with two Mission and display processors (DMC) via RS-485 full duplex serial links. 


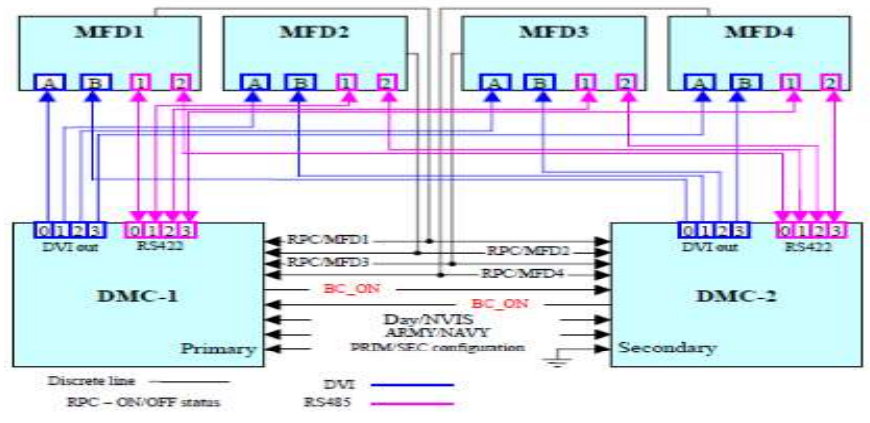

Figure 2.3: MFD Hardware configuration.

\section{MFD display page formats}

Based on the information received from the various on-board sensors and processing inside the DMC, the parameters are displayed on the four MFDs and two CDUs in the form of display pages. The concept of the display formats on MFD consists of primary pages that could be accessed through dedicated OSS's enabling quick swapping between the primary pages. Some of the primary pages have sub pages that are accessed in a "tree" concept.

There are 5 primary pages in the MFD accessed through dedicated OSS's. The title and box colors shall be green.

$>$ Primary Flight Display (PFD)

$>$ Systems page (SYS)

$>$ Menu page display (MENU)

$>$ Weather Radar Display (WR)

$>$ Digital Moving Map (MAP)

III. EXPERIMENTAL SETUP

A. DESCRIPTION OF THE TEST KIT

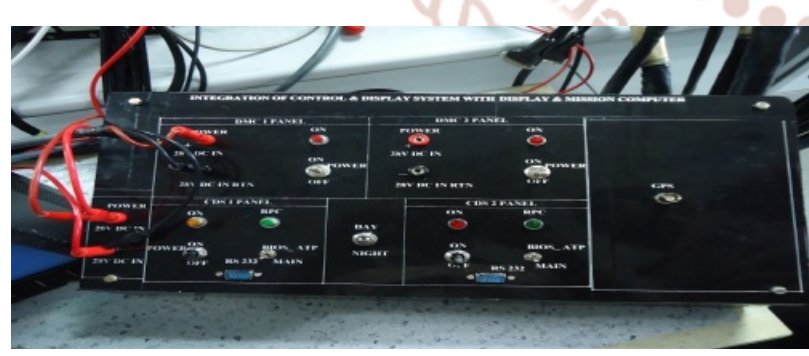

Figure3.1: Front View of the

\section{Test kit description}

The test panel is partitioned into two slots, one hosting power supply for CDS and DMC and other hosting software loading panel.

The power supply slot is provided with $28 \mathrm{~V}, 15 \mathrm{~A}$ banana sockets for power supply to the DMC. Single pole 3 position toggle switch is used for switching $\mathrm{ON}$ and OFF the DMC. Components used

\begin{tabular}{|c|l|l|c|}
\hline $\begin{array}{c}\text { S. } \\
\text { No. }\end{array}$ & \multicolumn{1}{|c|}{ NAME } & \multicolumn{1}{|c|}{ PART } & QUANTITY \\
\hline 1 & $\begin{array}{l}28 \mathrm{~V}, 15 \mathrm{~A} \\
+\mathrm{ve} \\
\text { terminal }\end{array}$ & $\begin{array}{l}\text { Banana socket } \\
\text { red color }\end{array}$ & 3 \\
\hline 2 & $\begin{array}{l}28 \mathrm{~V}, 15 \mathrm{~A}- \\
\text { ve terminal }\end{array}$ & $\begin{array}{l}\text { Banana socket } \\
\text { black color }\end{array}$ & 3 \\
\hline 3 & RS 232 & $\begin{array}{l}\text { Serial } \\
\text { Communication } \\
\text { port }\end{array}$ & 2 \\
\hline 4 & $\begin{array}{l}\text { Connector } \\
\text { J1 }\end{array}$ & $\begin{array}{l}\text { Power loom } \\
\text { J6 }\end{array}$ & 1 \\
\hline 5 & $\begin{array}{l}\text { Connector } \\
\text { J7 }\end{array}$ & $\begin{array}{l}\text { Discrete loom } \\
\text { Communication }\end{array}$ & 1 \\
\hline 7 & 24 AC/dc & & 6 \\
\hline
\end{tabular}

\section{Wiring}

The internal circuitry is to be done as per the wiring diagram.

Wiring procedure:

$>$ 20, 22 gauge cables are stripped using stripper.

As per the wiring diagram, the cables are soldered to the respective components.

The cables are crimped and spliced so that they are connected to the corresponding connectors.

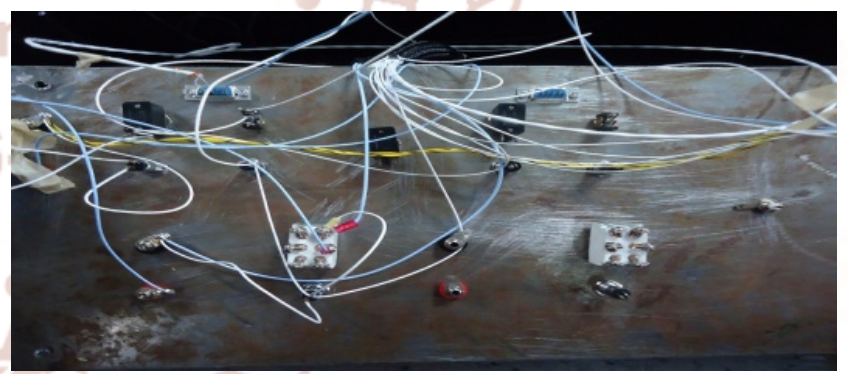

Figure 3.2: Internal circuitry of the test kit

\section{Test Setup:}

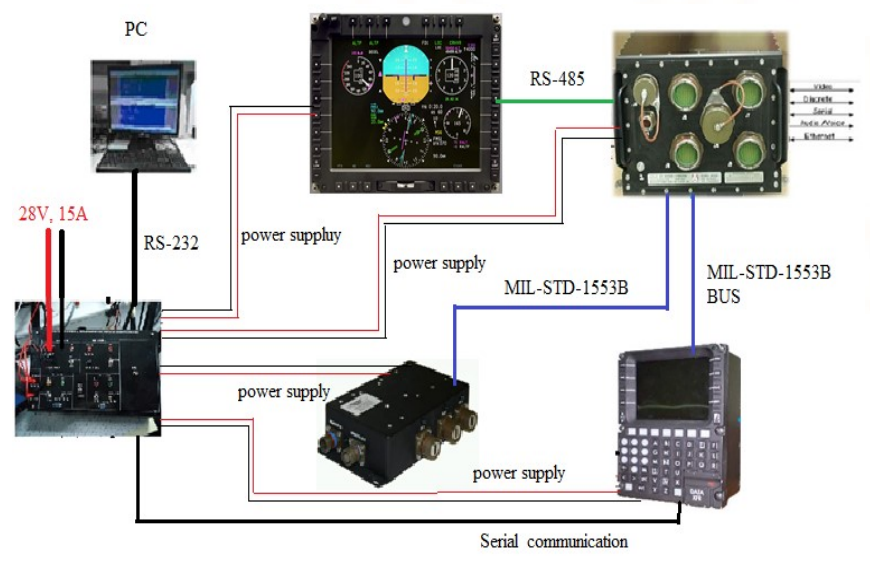

Figure 3.3: test setup 


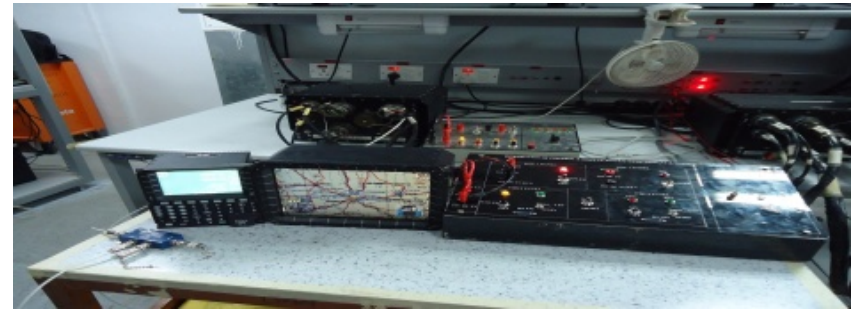

Figure 3.4: Powered Test setup

\section{TEST PROCEDURE:}

\section{A. Software loading}

1. Required equipment for environment installation

i. IBM-PC or compatible (any make) with the following specifications:

$>\mathrm{CPU}-$ Pentium $166 \mathrm{MHz}$ or higher.

$>64 \mathrm{MB}$ DRAM

$>17$ " SVGA monitor

$>$ Diskette drive of $1.44 \mathrm{MB} 3.5$ "

$>$ CDROM driver.

$>$ One serial RS-232 I/O port

ii. CDS Interface Box

iii. CDS golden unit

iv. Power Supply unit for 10-30VDC /6A (2 channels).

v. Jack terminals for power supply (PS) to Interface box connection.

vi. Interface cable between CDS and interface box.

\section{Required Software}

i. CDS Test Software CD

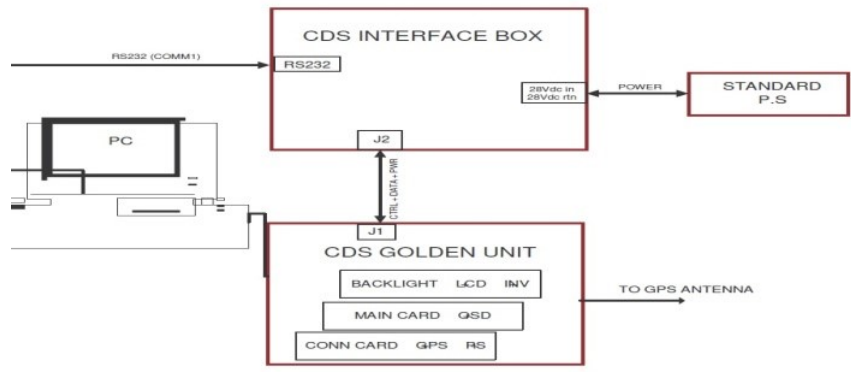

Figure 4.1: Set-Up for Software Loading

\section{RESULT ANALYSES}

\subsection{Integrated Test Facility for IADS}

It describes how integrating and communicating between the each devices. Output of this project is only about integration between the LRUs how there are communicating one another through standard connectors as mentioned in the above section.

\section{A. Establishing communication between DMC with MFD}

When DMC1 switch is pull up (OFF), 4 MFD's will off. There is no any communication between DMC and MFD's.

\section{B. Establishing communication between DMC with CDS}

> In CDS shows which one DMC is master 1 and master 2, we can in the maintenance page

Go to "maintenance (MNT) key"

Select" Data base sync" option

In that page "DMC 1 Master

SW: 03.90

DMC2 OFF" shows which one DMC is master.

$>$ If $\mathrm{DMCl}$ will pull up (OFF), there is no communicating between CDS and DMC. CDS will become TIMEOUT.

C. Changing over of DMC1 and DMC2 as master and observe CDS is OFF.

DMC1-OFF

$\mathrm{DMC} 2-\mathrm{ON}$ (master)

CDS-OFF

D. Invoking the self-test of individual MFD's

In MFD press "menu" button

In that select "maintenance page"

7 Press "VERSION" option to see the LRU's versions (same for all MFD's)

DMC1 S/w version 3.90

MFD s/w version 2.08 (for all

MFD's has same version)

CDS s/w version 01.16

DIU-OFF

DMM1 s/w version 01.27
E. Self-test keys of CDS

$>$ Go-to "Maintenance" page

$>$ In that press "test" key (page 2)

$>$ Select "CDU" option

$>$ Press "YES"

$>$ Press all keys in CDS

$>$ Press "FINISH" button.

\section{F. Testing of 4 MFD's}

$>$ In CDS press "Maintenance" key

$>$ Select "TEST" (page 2)

$>$ Press "MFD1" 
$>$ Then it will "testing" process, while processing MFD1 is OFF. Once testing process will finished "OK" after this condition MFD1 get ON.

This same procedure is same for all MFD's.

\section{G. If MIL-STD-1553B is removed from the coupler (CDS-DMC) the connection will be failed, there is no any communication between devices.}

\section{FUTURE SCOPE AND CONCLUSION}

The current test kit has a provision for connecting CDS and DMC only, the same test kit can be extended to connect MFD's and DIU by using extra looms, ARINC analyzer to stimulate the inputs which are fed to DIU and the complete cockpit can be stimulated at the test bench.

This test kit is very useful to stimulate the faults which occur at the helicopter ground level and integrated testing is also possible.

The current setup has also a provision wherein one more CDS can be connected to another DMC.

The test kit is capable of uploading software and it is portable which is directly used in helicopter. This test kit can be carried to Bases i.e., military base, naval base etc. There is no need of removal and transportation of DMC from helicopter by which it reduces cost and men power. It also reduces damage occurring to the DMC during transportation.

The design of test kit has been completed based on analysis of various components. The respective diagrams are also shown for detailed study of the kit. Here, it has been concluded that the kit is very much necessary for testing the proper working of the CDS and DMC which reduces the risk and cost. Finally this design is fulfilling all the objectives, which are needed for the testing.

$>$ Real time application as in helicopter is stimulated using DMC and CDS.

$>$ Real time GPS values can be tested or observed through our test bench.
Feeding the lat long values on CDS map can be viewed.

$>$ Testing of MIL-BUS 1553 can be carried out.

$>$ Software can be loaded on the CDS.

$>$ ATP testing of CDS can be done.

\section{REFERENCES}

1. IADS configuration manual, DMC manual, CDS manual, MFD manual, DIU manual.

2. Wallace, lane. "Airborne Trailblazer: two Decades with NASA Langley's 737 Flying Laboratory" NASA. prior to the 1970s, air transport operations were not considered sufficiently demanding to require advanced equipment like electronic flight displays. In other words, the growing numbers of cockpit elements were competing for cockpit space and pilot attention. Retrieved 1998-04-22.

3. Katz, peter. "Plane and pilot magazine-glasscockpit blackout" planeandpilotmag.com. Retrieved 2009-08-12.

4. Fred George "less is more: merit in cockpit minimalism" business and commercial Aviation". Aviation week network (Mar 23, 2017).

5. God fey, Kara "FLIGHTS REVEALED: Pilot reveals what REALLY goes on in a cockpit...and it may surprise you". The Express. Retrieved 30 August 1998.

6. S. A. Cavell Midshipmen and Quarterdeck Boys in the British Navy, 1771-1831, p. 12, "A survey of conventional instruments analysis"

7. Richards, Giles "FIA defends decision to enforce F1 halo cockpit protection device for 2018". The Guardian. Retrieved 30 August 2017.

8. David D. Allyn Yardarm and Cockpit Hardcover, p. 225, at Google Books

9. Bob Wartinger A Driver's Guide to Safe Boat Racing (2008), p. 17.

10. Charles F. Spence "The Right Seat Handbook: A White-Knuckle Flier's Guide to Light Planes". McGraw Hill Professional. ASIN 0070601488. ISBN 978-0-07-060148-2. 